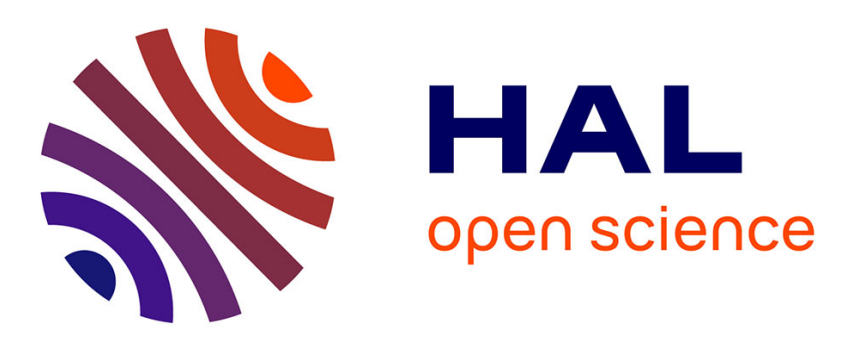

\title{
Epoxidation of vegetable oils under microwave irradiation
}

Sébastien Leveneur, Alain Ledoux, Lionel Estel, Bechara Taouk, Tapio Salmi

\section{To cite this version:}

Sébastien Leveneur, Alain Ledoux, Lionel Estel, Bechara Taouk, Tapio Salmi. Epoxidation of vegetable oils under microwave irradiation. Chemical Engineering Research and Design, 2014, 92 (8), pp.1495-1502. 10.1016/j.cherd.2014.04.010 . hal-02328198

\section{HAL Id: hal-02328198 \\ https://hal.science/hal-02328198}

Submitted on 19 Jan 2022

HAL is a multi-disciplinary open access archive for the deposit and dissemination of scientific research documents, whether they are published or not. The documents may come from teaching and research institutions in France or abroad, or from public or private research centers.
L'archive ouverte pluridisciplinaire HAL, est destinée au dépôt et à la diffusion de documents scientifiques de niveau recherche, publiés ou non, émanant des établissements d'enseignement et de recherche français ou étrangers, des laboratoires publics ou privés. 


\section{Epoxidation of vegetable oils under microwave irradiation}

Sébastien Leveneur ${ }^{a, b *}$, Alain Ledoux ${ }^{a}$, Lionel Estel $^{a}, B_{\text {Bechara Taouk }}^{a}$, Tapio Salmi ${ }^{b}$

aLSPC-Laboratoire de Sécurité des Procédés Chimiques, EA4704, INSA Rouen, 685 Avenue de l'Université, 76801 Saint-Etienne-du-Rouvray, France.Tel: +33 2 329566 54; Fax: +33 2329566 52; E-mail: sebastien.leveneur@insa-rouen.fr baboratory of Industrial Chemistry and Reaction Engineering, Process Chemistry Centre, Åbo Akademi University, Biskopsgatan 8, Fl-20500 Åbo/Turku, Finland.

\section{ABSTRACT}

This paper presents a study of the epoxidation of vegetable oil in an isothermal batch reactor system equipped with microwave or conventional heating. The epoxidation reaction was performed by peroxycarboxylic acid formed in situ from carboxylic acid and hydrogen peroxide. It was demonstrated that microwave irradiation can accelerate the epoxidation velocity when the continuous phase is aqueous, which is not transparent to microwave. This tendency was observed for peroxyacetic and peroxypropionic acids.

Keywords: Process intensification, Microwave, Epoxidation, Biolubricant 


\section{INTRODUCTION}

Energy saving, use of biomass resources and non-toxic chemicals are the main challenges and perspectives for the chemical industry. The majority of chemical processes are still using conventional heating, loosing energy to heat the vessel walls of the reactor, the inserts, the solvent and the catalyst. Microwave technology could provide an alternative to optimize the energy consumption. Indeed, there is no direct contact between the energy source and the reaction mixture, vanishing thermal convection. Furthermore, according to the dielectric permittivity of the matter, a rapid heating rate and selective heating can be achieved. The use of microwave in the field of organic synthesis is extensively described in literature, e.g., roughly 6000 articles have been published since 1998. The debate between the existence or non-existence of a non-thermal microwave effect is still going on. One should mention the work of Prof. Kappe on the use of microwave irradiation on organic synthesis [1].

This study is focused on illustrating the selective heating of microwave during a liquid-liquid reaction, namely epoxidation of vegetable oils by peroxycarboxylic acids.

The ability to convert electromagnetic energy into thermal energy depends on the dielectric properties of each material and it can be described by using the complex permittivity $(\varepsilon)$. The real part $\left(\varepsilon^{\prime}\right)$ characterizes a material ability to store charge, and the imaginary part $(\varepsilon ")$ defines effectiveness of a material to convert 
electromagnetic energy into heat. The dielectric properties are dependent on composition, temperature and frequency.

Thus, some materials can be transparent or absorbent to microwave, which could be an advantage in a multiphase reaction system [1-5], such as epoxidation of vegetable oils.

Epoxidized vegetable oils are used for various purposes, such as lubricants [6], as intermediates for polymer synthesis, as plasticizers and as scavengers in the synthesis of PVC. Indeed, the world consumption of lubricants is estimated to be 40 million tons per year used in different applications, from car engines to office chairs. As in fuel industry, the majority of lubricants used are petroleum-derived. Depletion of oil will increase the price of petroleum raw material and several studies have shown that $30-40 \%$ of lubricants escape into the environment through such routes as spills, leaks and evaporation [7]. For these reasons, researchers have focused on inexpensive, non-toxic and renewable sources of lubricants, i.e., bio-based lubricants. At present, the cost of bio-based lubricants is higher than petro-based lubricants, but compared to the maintenance and energy costs, it is a minor factor [7].

Prileshajev oxidation is the most used method to epoxidize vegetable oils. The method is based on the use of peroxycarboxylic acids formed in situ. This method is greener than using halohydrin, safer than molecular oxygen and more efficient than the use of inorganic peroxides. Epoxidation of vegetable oils by conventional heating has been studied by several research groups [8-27]. 
According to a literature review, epoxidation under microwave irradiation is rare [28-29]. Saifuddin et al. [28] have mostly focused their research on developing a finite element model to predict the temperature profile and Pillai et al. [29] have studied the epoxidation of olefin over different hydrotalcite catalysts under microwave irradiation. However, these articles did not propose a comparison between conventional and microwave heating, which is an important issue. Epoxidation of vegetable oil is an exothermic multiphase reaction system. Most carboxylic acids used are formic and acetic acids. Experiments carried out with formic acid are more exothermic than the ones carried out with acetic acid. Thus, in case of temperature control lost, thermal runaway could occur. Could microwave irradiation improve mass transfer? Thus, it would be possible to run experiments at lower temperature or to use less reactive peroxide species.

The goal of this article is to propose a comparison between conventional and microwave heating by studying different carboxylic acids and organic-to-aqueous phase ratios. For this purpose, experiments were carried out in an isothermal batch reactor under microwave and conventional heating. To follow the epoxidation reaction, a monosaturated fatty acid, i.e., oleic acid was selected as a test molecule. For the sake of simplicity, the reaction temperature was fixed to $60^{\circ} \mathrm{C}$. 


\section{EXPERIMENTAL SECTION}

\subsection{Apparatus and experimental procedures}

Experiments were carried out in a glass batch reactor equipped with a glass agitator, fiber optic as a temperature probe and a reflux condenser. Figure 1 shows a schematic view of the microwave reactor system. To minimize any deviation of electromagnetic waves, a transparent material, e.g., glass, must be used.

Fig. 1. Schematic view of the microwave heating and reactor system.

As shown in Fig. 1, the microwave heating system consists of a magnetron working at $2.45 \mathrm{GHz}$ with a variable input power in the range 0-1950 W. Microwaves are carried in a WR 340 waveguide applicator for a resonant single mode TE103 propagation which ensures a high intensity of electric field for the sample. Cylindrical samples are introduced through a metallic chimney to prevent microwave leakage. A short-circuit is used to optimize microwave power in the sample by keeping the reflected power to a minimum. The circulator protects the magnetron by diverting the reflected power into a water load. This system is also equipped with probes to measure the reflected and the incident powers. 
To have a rigorous comparison between conventional and microwave heating, the same reactor system was used in both cases. To prevent contamination induced by alkaline and metal components, which could initiate catalytic decomposition of peroxycarboxylic acid and hydrogen peroxide, all parts of the reactor system being in contact with the reaction solution were washed with hydrochloric acid, followed by another washing, with a phosphate-free detergent solution.

The addition procedure was the same for all the experiments. Firstly, carboxylic acid, water and oleic acid were added into the reactor, and when the desired temperature was reached, the preheated hydrogen peroxide solution was added. Table 1 introduces the experimental matrix.

Table 1. Experimental matrix.

\subsection{Analytical methods}

Samples were withdrawn from the reaction mixture by a plastic syringe (to avoid contamination of the solution by trace of metals). The concentration of hydrogen peroxide was determined by titration using a standard solution of ammonium cerium sulphate $(0.1 \mathrm{~N})$. The concentrations of oxirane and unsaturated groups, e.g., double bounds, were measured by FTIR (absorption band at 844 and 3006 $\mathrm{cm}^{-1}$, respectively). 


\section{RESULTS AND DISCUSSION}

\subsection{Mechanism and kinetics}

As mentioned previously, it is a liquid-liquid reaction system, where mass transfer plays an important role and different reactions occur in the aqueous and organic phases. The epoxidation of vegetable oil is done by peroxycarboxylic acid, which acts as an oxygen carrier because the solubility of hydrogen peroxide in the organic phase is low or negligible [14-26]. This peroxycarboxylic acid is formed in situ in the aqueous phase by carboxylic acid perhydrolysis, and then transferred to the organic phase. The peroxycarboxylic acid epoxides the unsaturated group to form an oxirane group. Dissociation of carboxylic acid leads to production of hydroxonium ions leading to the activation of the oxirane group. The activated oxirane group can undergo ring-opening reaction by different nucleophilic agents such as water, hydrogen peroxide and carboxylic acid. Depending on the reaction conditions and nature of the carboxylic acid, peroxycarboxylic acid can undergo decomposition reaction in the aqueous phase. Fig. 2 proposes a schematic view of the mechanism. Fig. 3 shows the different ways of ringopening reactions.

Fig. 2. Simplified reaction scheme.

Fig. 3. Ring-opening reactions. 
The goal of this paper is not to propose a kinetic model. However, for the sake of comprehensibility, kinetics and mass balance equation should be presented.

\section{Kinetics}

The rate expression for each reaction can be described as follows [26]:

Perhydrolysis of carboxylic acid,

$r_{\text {perh }}=k_{\text {perh }} \cdot\left(\left[\mathrm{RCO}_{2} \mathrm{H}\right]_{\mathrm{aq}}\left[\mathrm{H}_{2} \mathrm{O}_{2}\right]_{\mathrm{aq}}-\frac{1}{\mathrm{~K}^{\mathrm{C}}}\left[\mathrm{RCO}_{3} \mathrm{H}\right]_{\mathrm{aq}} \cdot\left[\mathrm{H}_{2} \mathrm{O}\right]_{\mathrm{aq}}\right)$

Decomposition of peroxycarboxylic acid,

$\mathrm{r}_{\text {decomp }}=\mathrm{k}_{\text {decomp }} \cdot\left[\mathrm{RCO}_{3} \mathrm{H}\right]_{\mathrm{aq}}$

Kinetic of peroxycarboxylic acid decomposition decreases with the increase of carbon chain [29]

Epoxidation of oleic acid,

$\mathrm{r}_{\mathrm{ep}}=\mathrm{k}_{\mathrm{ep}} \cdot\left[\mathrm{RCO}_{3} \mathrm{H}\right]_{\text {org }} \cdot[\text { oleic acid }]_{\mathrm{org}}$

Ring opening,

$\mathrm{r}_{\mathrm{R} . \mathrm{O}}=\mathrm{k}_{\mathrm{RO}} \cdot[\text { Epoxide }]_{\text {org }} \cdot\left[\mathrm{H}_{3} \mathrm{O}^{+}\right]_{\mathrm{aq}}$

where $\left[\mathrm{H}_{3} \mathrm{O}^{+}\right]$is mainly due to the dissociation of carboxylic acid. This reaction occurs with strong carboxylic acid, e.g., formic acid. Based on the work of Santacesaria [14-15], ring-opening reaction occurs at the liquid-liquid interface. The first step is the activation of oxirane group. 


\section{Mass balance}

Fig. 4 shows the different mass transfer phenomena based on the film theory. Aqueous species such as peroxycarboxylic acid, carboxylic acid and water diffuse from aqueous to organic phase. Based on the observation of several authors [16-25], hydrogen peroxide solubility in vegetable oil is low, thus direct epoxidation by hydrogen peroxide is not possible. Solubility of organic species such as oleic acid, epoxidized oleic acid and ring opening products can be assumed negligible in the aqueous phase.

Fig. 4. Concentration profiles for aqueous species.

Mass balance on the species present in the aqueous phase gives:

$$
\begin{aligned}
& \frac{\mathrm{d}[\mathrm{CA}]_{\mathrm{aq}}}{\mathrm{dt}}=-\mathrm{r}_{\mathrm{perh}}-\mathrm{k}_{\mathrm{aq}-\mathrm{FA}} \cdot \frac{\mathrm{V}_{\mathrm{tot}}}{\mathrm{V}_{\mathrm{aq}}} \cdot \mathrm{a}_{0} \cdot\left([\mathrm{CA}]_{\mathrm{aq}}-[\mathrm{CA}]_{a q}^{*}\right) \\
& \frac{\mathrm{d}[\mathrm{HP}]_{\mathrm{aq}}}{\mathrm{dt}}=-\mathrm{r}_{\text {perh }} \\
& \frac{\mathrm{d}[\mathrm{W}]_{\mathrm{aq}}}{\mathrm{dt}}=-\mathrm{r}_{\text {perh }}-\mathrm{k}_{\mathrm{aq}-\mathrm{W}} \cdot \frac{\mathrm{V}_{\text {tot }}}{\mathrm{V}_{\mathrm{aq}}} \cdot \mathrm{a}_{0} \cdot\left([\mathrm{W}]_{\mathrm{aq}}-[\mathrm{W}]_{a q}^{*}\right) \\
& \frac{\mathrm{d}[\mathrm{PCA}]_{\mathrm{aq}}}{\mathrm{dt}}=\mathrm{r}_{\text {perh }}-\mathrm{r}_{\text {decomp }}-\mathrm{k}_{\mathrm{aq}-\mathrm{PCA} \cdot} \cdot \mathrm{V}_{\text {tot }} \cdot \mathrm{a}_{0} \cdot\left([\mathrm{PCA}]_{\mathrm{aq}}-[\mathrm{PCA}]_{a q}^{*}\right) \\
& {\left[\mathrm{i}^{*} \text { aq }\right. \text { represents the concentration at the interface liquid liquid. }}
\end{aligned}
$$


Mass balance in the organic phase can be derived as:

$$
\begin{aligned}
& \frac{d[C A]_{\text {org }}}{d t}=k_{\text {org-CA }} \cdot \frac{V_{\text {tot }}}{V_{\text {org }}} \cdot a_{0} \cdot\left([C A]_{\text {org }}^{*}-[C A]_{\text {org }}\right)+r_{\text {Ep }} \\
& \frac{d[P C A]_{\text {org }}}{d t}=k_{\text {org-PCA }} \cdot \frac{V_{\text {tot }}}{V_{\text {org }}} \cdot a_{0} \cdot\left([P C A]_{\text {org }}^{*}-[P C A]_{\text {org }}\right)-r_{\text {Ep }} \\
& \frac{d[W]_{\text {org }}}{d t}=k_{\text {org- }} \cdot \frac{V_{\text {tot }}}{V_{\text {org }}} \cdot a_{0} \cdot\left([W]_{\text {org }}^{*}-[W]_{\text {org }}\right) \\
& \frac{d[O A]_{\text {org }}}{d t}=-k_{\text {org-OA }} \cdot \frac{V_{\text {tot }}}{V_{\text {org }}} \cdot a_{0} \cdot\left([O A]_{\text {org }}-[O A]_{\text {org }}^{*}\right)-r_{\text {Ep }} \\
& \frac{d[D e g]_{\text {org }}}{d t}=-k_{\text {org-Deg }} \cdot \frac{V_{\text {tot }}}{V_{\text {org }}} \cdot a_{0} \cdot\left([D e g]_{\text {org }}-\left[[D e g]_{\text {org }}^{*}\right)+r_{R . O}\right. \\
& \frac{d[E O A]_{\text {org }}}{d t}=-k_{\text {org-EOA }} \cdot \frac{V_{\text {tot }}}{V_{\text {org }}} \cdot a_{0} \cdot\left([E O A]_{\text {org }}-[E O A]_{\text {org }}^{*}\right)+\left(r_{\text {Ep }}-r_{\text {R.O }}\right)
\end{aligned}
$$

where CA, PCA, OA, EOA, HP, W, Deg, represent respectively carboxylic acid, peroxycarboxylic acid, oleic acid, epoxydized oleic acid, hydrogen peroxide, water and ring opening products. [i] ${ }^{*}$ org denotes concentration of organic species at the interface.

Mass transfer coefficient in the continuous aqueous phase

Relation of Calderbank and Moo-Young can be used to estimate the value of the mass transfer coefficient in the continuous aqueous phase:

$\mathrm{k}_{\mathrm{c}-\mathrm{i}}=1.3 \times 10^{-3}\left[\frac{P \mu_{\mathrm{c}}}{\mathrm{V}_{\mathrm{c}} \mathrm{\rho}_{\mathrm{c}}}\right]^{\frac{1}{4}}\left[\frac{\mu_{\mathrm{c}}}{\mathrm{D}_{\mathrm{m}-\mathrm{i}} \mathrm{\rho}_{\mathrm{c}}}\right]^{\frac{-2}{3}}$ 
where, $\mu_{\mathrm{c}}\left(\mathrm{kg} \cdot \mathrm{m}^{-1} \cdot \mathrm{s}^{-1}\right), \mathrm{V}_{\mathrm{c}}\left(\mathrm{m}^{3}\right)$ and $\rho_{\mathrm{c}}\left(\mathrm{kg} \cdot \mathrm{m}^{-3}\right)$ are viscosity, volume and density of the continuous aqueous phase, respectively. Parameter $P\left(\mathrm{~kg} \cdot \mathrm{m}^{2} \cdot \mathrm{s}^{-3}\right)$ is the power dissipated by the agitator and $D_{m-i}\left(m^{2} \cdot s^{-1}\right)$ is the diffusion coefficient in the multicomponent liquid mixture [30].

The factor $P$ is equal to $P=\psi P_{\mathrm{m}} \mathrm{n}_{\mathrm{a}}^{3} \mathrm{D}_{\mathrm{a}}^{5}$

where $\psi$ is the agitator power consumption number, $\rho_{m}\left(\mathrm{~kg} \cdot \mathrm{m}^{-3}\right)$ is the density of the mixture, $n_{a}$ is the stirring velocity and $D_{a}$ the stirrer diameter.

In the sake of clarity, the diffusion coefficient $D_{m-i}$ in the multicomponent liquid mixture can be estimated by the equation of Perkins-Geankoplis [30]. Different type of diffusion coefficient could be used [30]. All of them have the same structure:

$\mathrm{D}_{\mathrm{A} / \mathrm{B}}^{0}=$ Constant $\frac{\mathrm{T}}{\mu_{\mathrm{B}}^{\alpha}}$

Mass transfer coefficient in the dispersed organic phase

Organic droplet can be assumed to be rigid, thus Treybal correlation can be used to estimate the mass transfer coefficient.

$\mathrm{k}_{\mathrm{d}-\mathrm{i}}=\frac{2 \pi^{2} \mathrm{D}_{\mathrm{m}-\mathrm{i}}}{3 \mathrm{~d}_{32}}$

where $d_{32}$ is the Sauter number $(m)$ equal to $\frac{\sum n_{i} d_{i}^{3}}{\sum n_{i} d_{i}^{2}}$ where $n_{i}$ represents the number of drops with diameter $d_{i}$. The Sauter number $d_{32}$ can be calculated as:

$\frac{\mathrm{d}_{32}}{\mathrm{D}_{\mathrm{a}}}=\frac{\mathrm{Af}\left(\Phi_{\mathrm{d}}\right)}{\mathrm{We}^{0.6}}$

where $D_{a}$ is the stirrer diameter, $A$ is a parameter varying between 0.04 and 0.4 . 
The Weber number (We) is expressed as:

$$
\mathrm{We}=\frac{\rho_{\mathrm{c}} \mathrm{n}_{\mathrm{a}}^{2} \mathrm{D}_{\mathrm{a}}^{3}}{\sigma}
$$

where $\rho_{c}$ is the density of the continuous phase, $n_{a}$ is the stirring velocity and $\sigma$ is the surface tension $\left(\mathrm{N} . \mathrm{m}^{-1}\right)$ of the system.

The function $\mathrm{f}\left(\Phi_{\mathrm{d}}\right)$ is equal to

$$
\mathrm{f}\left(\Phi_{\mathrm{d}}\right)=\left[\frac{1 \mathrm{n}\left(+\mathrm{CC}_{3} \Phi_{\mathrm{d}}\right)}{1 \mathrm{n}_{2} \mathrm{C}}\right]^{\frac{-3}{5}}
$$

where $C_{2}$ is equal to 0.011 and $C_{3} \rightarrow 1$ in case of $\phi_{d}>0.3$.

The purpose of this paragraph is to show that microwave irradiation could have an influence on kinetic and mass transfer parameters. Even though, all experiments were carried out under isothermal condition, one should remind that measured temperature is a global signal and local gradient temperature could occur. This local gradient temperature could have an influence on diffusion coefficients and interfacial surface tension. Binner et al. [31] confirmed that microwave irradiation has a selective heat effect on aqueous organic phases. In such liquid-liquid reaction system, rotating speed plays an important role on mass transfer. To evaluate the influence of turbulence, the adimensional Reynolds number was used. To evaluate this number, one should calculate viscosity of the system. Viscosity has an influence on mass transfer coefficient and Sauter number. Viscosity of organic phase increases with conversion of oleic acid to ring opening products. Based on the work of Campanella et al. [25], at $50^{\circ} \mathrm{C}$ high oleic sunflower oil is 0.02 Pa.s, epoxidized high oleic sunflower oil is 
0.1 Pa.s and acetylated high oleic sunflower is 1 Pa.s. Density of organic phase is quite constant.

In the same way, interfacial tension should change with the conversion of oleic acid. However, this parameter is difficult to measure.

However, only the initial and final Reynolds number can be calculated due to the change of viscosity.

$\mathrm{R}_{\mathrm{e}}=\frac{\rho_{\mathrm{m}} \cdot \mathrm{n}_{\mathrm{a}} \cdot \mathrm{D}_{\mathrm{a}}^{2}}{\mu_{\mathrm{m}}}$

Table 1 presents the value of Reynolds number at different rotating speed, organic-to-aqueous phase ratio, initial and final time, i.e, complete conversion to ring opening products. For the sake of simplicity, the results are presented in Table $1 . \mu_{m}$ and $\rho_{m}$ are respectively viscosity and density of reaction mixture. Viscosity and density of water were used for the aqueous phase, and can be assumed to be constant along the reaction time. For the organic phase, viscosity of oleic acid was used for initial Reynolds number and viscosity of ring opening products was used for final Reynolds number.

Density and viscosity of oleic acid are respectively $860 \mathrm{~kg} / \mathrm{m}^{3}$ and 0.01 Pa.s at $60^{\circ} \mathrm{C}$ according to Aspen plus software. Based on the work of Campanella et al.[25], viscosity of ring opening products can be assumed to be $1 \mathrm{~Pa}$.s.

Table 1. Evolution of the Reynolds number at $60^{\circ} \mathrm{C}$. 
One can notice a drastic evolution of Reynolds number between the beginning and the final experimental time. This shows that there is a decrease of turbulence in the reaction mixture. 
3.2 Influence of the input power

In case of microwave heating, temperature effects result from the interaction between the electromagnetic radiation and the matter. Thus, to control the temperature, one should tune the input power and control the absorbed and reflected power during the reaction. Figs 5 and 6 show the absorbed power from the reaction mixture during an experiment carried out with a $30 \mathrm{wt} . \%$ and $70 \mathrm{wt} . \%$ of the organic phase, respectively. Time zero corresponds to the addition of the carboxylic acid into the reaction mixture.

Fig. 5. Evolution of the temperature towards the absorbed and reflected power for a 30 wt. $\%$ of organic phase mixture at 400 and $650 \mathrm{rpm}$.

From Fig. 5, the first ten minutes correspond to an induction period corresponding to the tuning period. The average absorbed power was $10 \mathrm{~W}$.

Fig. 6. Evolution of the temperature towards the absorbed and reflected power for a 70 wt. $\%$ of organic phase mixture at 400 and $650 \mathrm{rpm}$. In case of experiments carried out with a reaction mixture containing $70 \mathrm{wt} . \%$ of the organic mixture, the power absorbed was around $10 \mathrm{~W}$.

The absorbed power in both cases was of the same order of magnitude. 


\subsection{Influence of the rotating speed}

The rotation speed is a parameter which governs the value of the mass transfer coefficient of the aqueous and organic phase [32-34]. Based on preliminary experiments, it was found that a minimum of $300 \mathrm{rpm}$ was needed to obtain a stable emulsion. In this section, the results concerning the conventional and microwave heating will be presented (Fig. 7).

Fig. 7. Effect of the stirring speed on the oleic acid conversion at $60^{\circ} \mathrm{C}$ in the presence of acetic acid.

Fig. 7 shows that the influence of the rotation speed is negligible in the range of 400-650 rpm under conventional heating. Thus, one can conclude that the size of the drop does not interfere with the kinetics in this rotation range. The initial Sauter numbers, measuring the average droplet diameter, can be estimated from Eq. (11) (Table 2). Based on Eq. (11), one can notice that Sauter number depends on continuous phase density, impeller diameter and interfacial surface tension.

The kinetics of the epoxide formation for experiments carried out at $400 \mathrm{rpm}$ was the same under conventional and microwave heating. However, the experiment carried out under microwave irradiation and at $650 \mathrm{rpm}$ presents a clearly accelerated conversion.

Table 2. Sauter number at different rotating speed. 
Under conventional heating, rotating speed does not have any influence in the range $400-650 \mathrm{rpm}$, this mean that the exchange surface area is optimal. This leads to the conclusion that microwave irradiation does not interfere on this parameter.

By increasing the rotating speeds (cf. Eq. (8)), impeller power consumption increases. Under microwave irradiation, energy delivered to reaction mixture could be more efficient than under conventional heating. For that reason, kinetic increased at $650 \mathrm{rpm}$ compared to $400 \mathrm{rpm}$. This explains why the epoxidation kinetics is faster at $650 \mathrm{rpm}$ under microwave irradiation than at $400 \mathrm{rpm}$. A better energy dissipation would improve aqueous mass transfer coefficient $\mathrm{k}_{\mathrm{aqueous}}$ due to a better homogenization of power delivered to reaction mixture. To have a better investigation of this phenomenon, change in aqueous to organic phase ratio was studied.

\subsection{Influence of organic-to-aqueous phase ratio}

As mentioned earlier, microwave irradiations are transparent to oil, i.e., $\varepsilon^{\prime}=2.8$ and $\varepsilon "=0.15$ for soybean oil [35]. Thus, one could expect different kinetic results according to the nature of the continuous phase. Experiments were carried out with 70 and $30 \mathrm{wt} \%$ of the organic phase, using the stirring speed of $650 \mathrm{rpm}$ to have an optimal exchange surface area. 
Fig. 8. Influence of the heating source and nature of the continuous phase on the oleic acid conversion in the presence of acetic acid at $650 \mathrm{rpm}$ and $60^{\circ} \mathrm{C}$.

Fig. 9. Influence of the heating source and nature of the continuous phase on the mole fraction of epoxide in the presence of acetic acid at $650 \mathrm{rpm}$ and $60^{\circ} \mathrm{C}$.

From Fig. 8, one can notice that in case of experiments carried out with $70 \mathrm{wt} . \%$ of the organic phase, the influence of microwave irradiation on the conversion rate was less pronounced than with experiment carried out with $30 \mathrm{wt} . \%$. Binner et al. [31] have demonstrated that there is a temperature gradient leading to a decrease of interfacial surface tension and a coalescence of the aqueous droplets. This coalescence diminishes the exchange surface area and thus limits mass transfer.

Fig. 9. presents the evolution of mole fraction of epoxide. Fig. 9 confirms that mass transfer phenomenon is improved under microwave irradiation than under conventional heating. Under microwave irradiation, energy dissipation is higher than under conventional heating, this increase the value of aqueous mass transfer coefficient at the interface leading to a better diffusion of hydroxonium ions and water to the organic phase. At both organic-to-aqueous phase ratios, the ring opening reaction increases. In order to confirm this hypothesis of mass transfer due to a better energy distribution, propionic acid will be tested. Propionic acid will produce peroxypropionic acid which is less reactive than peroxyacetic acid [29]. 


\subsection{Influence of the carboxylic acids}

Experiments without carboxylic acids were performed but there was no conversion of oleic acid. It can be noticed that the same tendency was observed for experiments carried out with propionic acid (Fig. 10), i.e., microwave irradiation increases the epoxidation velocity. However, this increase is slower than with acetic acid.

Fig. 10. Conversion of oleic acids under conventional and microwave heating $\underline{\text { using different carboxylic acid at } 650 \mathrm{rpm} \text { and } 60^{\circ} \mathrm{C}}$.

Fig. 11. Influence of the heating source and nature of the continuous phase on the mole fraction of epoxide at $650 \mathrm{rpm}$ and $60^{\circ} \mathrm{C}$.

Conversion of oleic acid is slightly improved by microwave irradiation due to faster mass transfer. In case of propionic acid (Fig. 10) ring opening reaction is faster under microwave irradiation than under conventional heating. As said earlier, peroxypropionic acid is less reactive than peroxyacetic acid but mass transfer of water from aqueous to organic phase occurs at similar velocity as with acetic acid. 
By calculating the initial reaction rates, for which the ring opening reaction can be assumed to be negligible, the kinetics of epoxide formation is 2.5 times higher under microwave irradiation than under conventional heating.

Table 4. Initial rate of epoxide formation. 


\section{CONCLUSIONS}

The epoxidation kinetics of vegetable oil under microwave and conventional heating was compared. Experiments were carried out in an isothermal batch reactor at different rotation speeds and different organic-to-aqueous phase ratios. It was shown that microwave irradiation does not have an influence on the experiments carried out with 70 wt.\% of organic phase. However, it was revealed that microwave exposure increases the reaction rate when the continuous phase is the aqueous one for the rotation speed of $650 \mathrm{rpm}$. This observation was explained by a higher energy dissipation under microwave irradiation.

This tendency was confirmed by using peroxypropionic and peroxyacetic acids, and it was shown that the epoxidation kinetics is increased by a factor of 2.5 under microwave irradiation. The modification of the energy repartition at the interface was confirmed by the increase of the ring opening reaction rate under microwave irradiation. 


\section{ACKNOWLEDGMENT}

The financial support from the Academy of Finland is gratefully acknowledged.

The authors express their gratitude to Bruno Daronat for his technical assistance. 


\section{REFERENCES}

1. Kappe, C.O., Dallinger, D., 2009. Controlled microwave heating in modern organic synthesis: highlights from the 2004-2008 literature. Mol. Divers 13, 71193.

2. Lidström, P., Tierney, J., Wathey, B., Westman, J., 2001. Microwave assisted organic synthesis-a review. Tetrahedron 57, 9225-9283.

3. Altman, E., Stefanidis, G.D., van Gerven, T., Stankiewicz, A.I., 2010. Process intensification of reactive distillation for the synthesis of $n$-Propyl propionate: the effects of microwave radiation on molecular separation and esterification reaction. Ind. Eng. Chem. Res. 49, 10287-10296.

4. Yadav, G.D., Borkar, I.V., 2009. Kinetic and mechanistic investigation of microwave-assisted lipase catalyzed synthesis of citronellyl acetate. Ind. Eng. Chem. Res. 48, 7915-7922.

5. Bonnet C., Estel L., Ledoux A., Mazari B., Louis A., 2004. Study of the thermal repartition in a microwave reactor: application to the nitrobenzene hydrogenation. Chem. Eng. Proc. 43, 1435-1440.

6. Okieimen F. E., Bakare O. I., Okieimen C. O., 2002. Studies on the epoxidation of rubber seed oil. Ind. Crop. Prod. 15(2), 139-144.

7. Scott F., 2003. One slick trick. Environ. Health Persp. 12(111), A654-A657.

8. Dinda S., Patwardhan A. V., Goud V. V., Pradhan N. C., 2008. Epoxidation of cottonseed oil by aqueous hydrogen peroxide catalysed by liquid inorganic acids. Bioresource Technol. 99, 3737-3744. 
9. Rüsch gen. Klaas M., Warnel S., 1999. Complete and partial epoxidation of plant oils by lipase-catalyzed perhydrolysis. Ind. Crop. Prod. 9, 125-132.

10. Hilker I., Borthe D., Prüss J., Warnecke H.-J., 2001. Chemo-enzymatic epoxidation of unsaturated plant oils. Chem. Eng. Sci. 56, 427-432

11. Goud V. V., Patwardhan A. V., Dinda S., Pradhan N. C., 2007. Kinetics of epoxidation of jatropha oil with peroxyacetic and peroxyformic acid catalysed by acidic ion exchange resin. Chem. Eng. Sci. 62, 4065-4076.

12. Lathi P. S., Mattiasson B., 2007. Green approach for the preparation of biodegradable lubricant base stock from epoxidized vegetable oil. Appl. Catal. BEnv. 69, 207-212.

13. Adhvaryu A., Erhan S. Z., 2002. Epoxidized soybean oil as a potential source of high-temperature lubricants. Ind. Crop. Prod. 15, 241-254.

14. Santacesaria E., Tesser R., Di Serio M., Turco R., Russo V., Verde D., 2011. A biphasic model describing soybean oil epoxidation with $\mathrm{H}_{2} \mathrm{O}_{2}$ in a fed-batch reactor. Chem. Eng. J. 173(1), 198-209.

15. Santacesaria E., Renken A., Russo V., Turco R., Tesser R., Di Serio M., 2012. Biphasic Model Describing Soybean Oil Epoxidation with $\mathrm{H}_{2} \mathrm{O}_{2}$ in Continuous Reactors. Ind. Eng. Chem. Res. 51(26), 8760-67.

16. Campanella A., Baltanás M.A., 2004. Degradation of the oxirane ring of epoxidized vegetable oils with solvated acetic acid using cation-exchange resins. Eur. J. Lipid Sci. Technol. 106(8), 524-30. 
17. Campanella A., Baltanás M.A., Capel-Sánchez M.C., Campos-Martín J.M., Fierro J.L.G., 2004. Soybean oil epoxidation with hydrogen peroxide using an amorphous Ti/SiO2 catalyst. Green Chem. 6(7), 330-34.

18. Campanella A., Baltanás M.A., 2005. Degradation of the oxirane ring of epoxidized vegetable oils in liquid-liquid systems: I. Hydrolysis and attack by $\mathrm{H}_{2} \mathrm{O}_{2}$. Latin Am. Appl. Res. 35(3), 205-10.

19. Campanella A., Baltanás M.A., 2005. Degradation of the oxirane ring of epoxidized vegetable oils with hydrogen peroxide using an ion exchange resin. Catal. Today 107-108, 208-14.

20. Campanella A., Baltanás M.A., 2005. Degradation of the oxirane ring of epoxidized vegetable oils in liquid-liquid systems: II. Reactivity with solvated acetic and peracetic acids. Latin Am. Appl. Res. 35(3), 211-16.

21. Campanella A., Baltanás M.A., 2006. Degradation of the oxirane ring of epoxidized vegetable oils in liquid-liquid heterogeneous reaction systems. Chem. Eng. J. 118(3), 141-52.

22. Campanella A., Baltanás M.A., 2007. Degradation of the oxirane ring of epoxidized vegetable oils in a liquid-liquid-solid heterogeneous reaction system. Chem. Eng. Process 46(3), 210-21.

23. Campanella A., Fontanini C., Baltanás M.A., 2008. High yield epoxidation of fatty acid methyl esters with performic acid generated in situ. Chem. Eng. J. 144(3), 466-75. 
24. Campanella A., Mandagarán B.A., Campanella E.A., 2009. Partitioning of carboxylic acid between oil and water phases. Experimental, correlation, and prediction. J. Am. Oil Chem. Soc. 86(6), 513-19.

25. Campanella A., Rustoy E., Baldessari A., Baltanás M.A., 2010. Lubricants from chemically modified vegetable oils. Bioresour. Technol. 2101(1), 245-54.

26. Leveneur S., Zheng J., Taouk B., Burel F., Wärnå J., Eränen K., Salmi T., 2014. Interaction of thermal and kinetic parameters for a liquid liquid reaction system: Application to vegetable oils epoxidation by peroxycarboxylic acid. J. Taiwan Inst. Chem. Eng., accepted.

27. Saifuddin N., Wei Zhan L., Xin Ning K., 2011. Heat-modelling of microwave assisted epoxidation of palm acid oil. Am. J. Appl. Sci. 8(3), 217-229.

28. Pillai U. R., Sahle-Demessie E., Varma R. J., 2002. Microwave-expedited olefin epoxidation over hydrotalcites using hydrogen peroxide and acetonitrile. Tetrahedron Lett. 43, 2909-2911.

29. Leveneur S., Wärnå J., Salmi T., Murzin D. Yu., 2010. A review: Catalytic synthesis and decomposition of peroxycarboxylic acids. Trends Chem. Eng. 13, $17-52$.

30. Leveneur S., de Araujo Filho C. A., Estel L., Salmi T., 2012. Modeling of a liquid-liquid-solid heterogeneous reaction system: application to the synthesis of peroxy fatty acids. Ind. Eng. Chem. Res. 51(1), 189-201.

31. Binner E.R., Robinson J.P., Silvester S.A., Kingman S.W., Lester E.H., 2014. Investigation into the mechanism by which microwave heatin enhances separation of water-in-oil emulsions. Fuel 116, 516-521. 
32. Calderbank P. H., Moo-Young M.B., 1961. The continuous phase heat and mass transfer properties of dispersions. Chem. Eng. Sci. 16, 39-54.

33. Treybal R. E., 1963. Liquid extraction, second ed., McGraw-Hill, New York.

34. Zaldivar J. M., Molga E., Alós M. A., Hernández H., Westerterp K. R., 1996. Aromatic nitrations by mixed acid. Fast liquid-liquid reaction engine. Chem. Eng. Proc. 35, 91-105.

35. Muley P. D., Boldor D., 2013. Investigation of microwave dielectric properties of biodiesel components. Bioresource Technol. 127, 165-174. 


\section{FIGURES}

Fig. 1. Schematic view of the microwave heating and reactor system.

Fig. 2. Simplified reaction scheme.

Fig. 3. Ring-opening reactions.

Fig. 4. Concentration profiles for aqueous species.

Fig. 5. Evolution of the temperature towards the absorbed and reflected power for a 30 wt. \% of organic phase mixture at 400 and $650 \mathrm{rpm}$.

Fig. 6. Evolution of the temperature towards the absorbed and reflected power for a 70 wt. $\%$ of organic phase mixture at 400 and $650 \mathrm{rpm}$.

Fig. 7. Effect of the stirring speed on the oleic acid conversion at $60^{\circ} \mathrm{C}$ in the presence of acetic acid.

Fig. 8. Influence of the heating source and nature of the continuous phase on the oleic acid conversion in the presence of acetic acid at $650 \mathrm{rpm}$ and $60^{\circ} \mathrm{C}$.

Fig. 9. Influence of the heating source and nature of the continuous phase on the mole fraction of epoxide in the presence of acetic acid at $650 \mathrm{rpm}$ and $60^{\circ} \mathrm{C}$.

Fig. 10. Conversion of oleic acids under conventional and microwave heating using different carboxylic acid at $650 \mathrm{rpm}$ and $60^{\circ} \mathrm{C}$.

Fig. 11. Influence of the heating source and nature of the continuous phase on the mole fraction of epoxide at $650 \mathrm{rpm}$ and $60^{\circ} \mathrm{C}$. 


\section{TABLES}

Table 1. Experimental matrix.

Table 2. Sauter number at different rotating speed.

Table 3. Initial rate of epoxide formation.

Table 4. Initial rate of epoxidized oleic acid formation. 


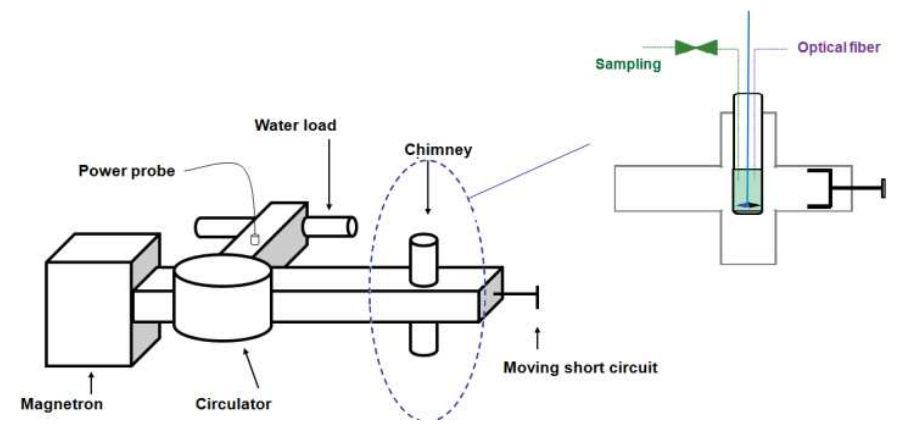

Fig. 1. Schematic view of the microwave heating and reactor system. 


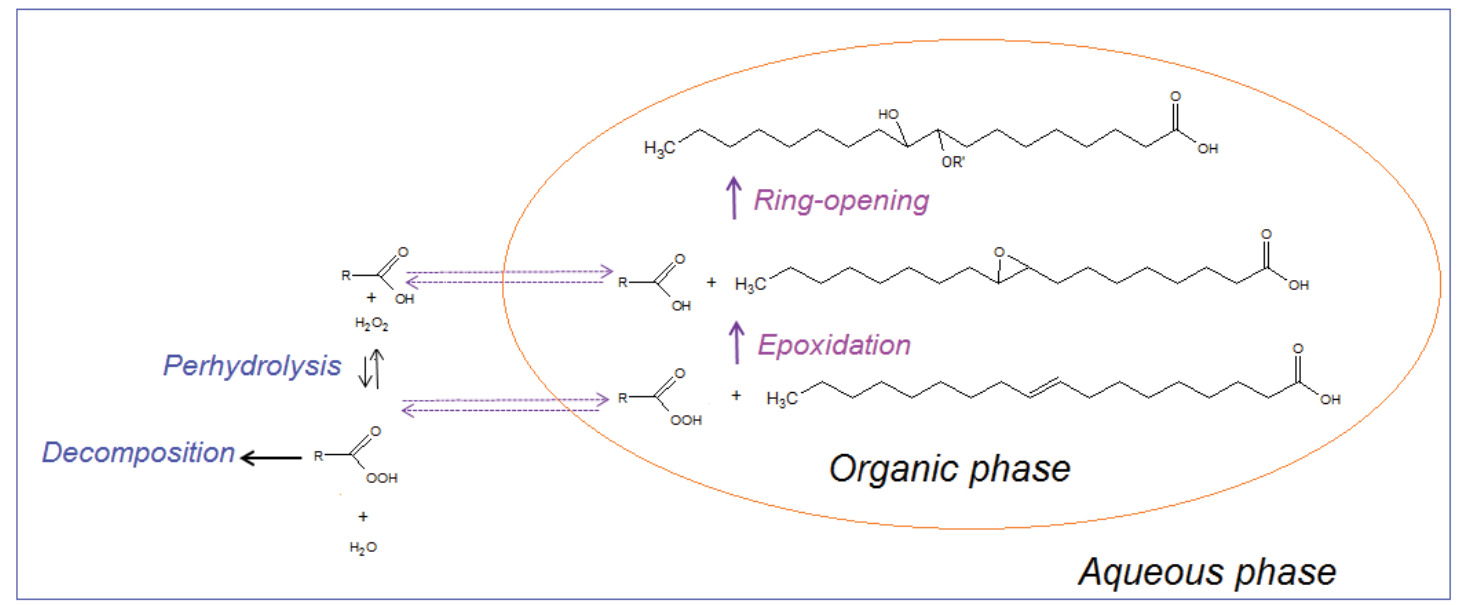

Fig. 2. Simplified reaction scheme. 


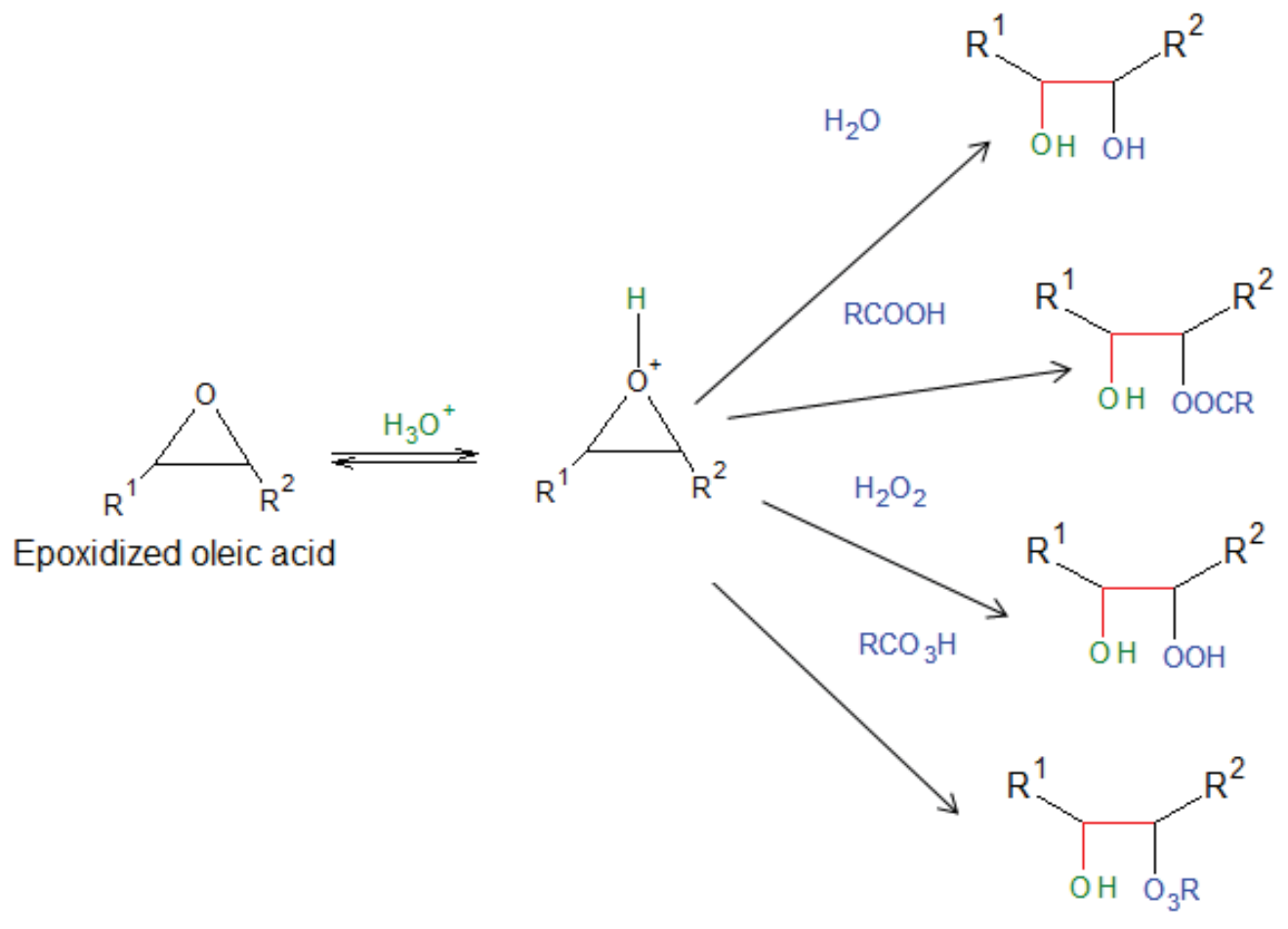

Degradation products: Deg

Fig. 3. Ring-opening reactions. 


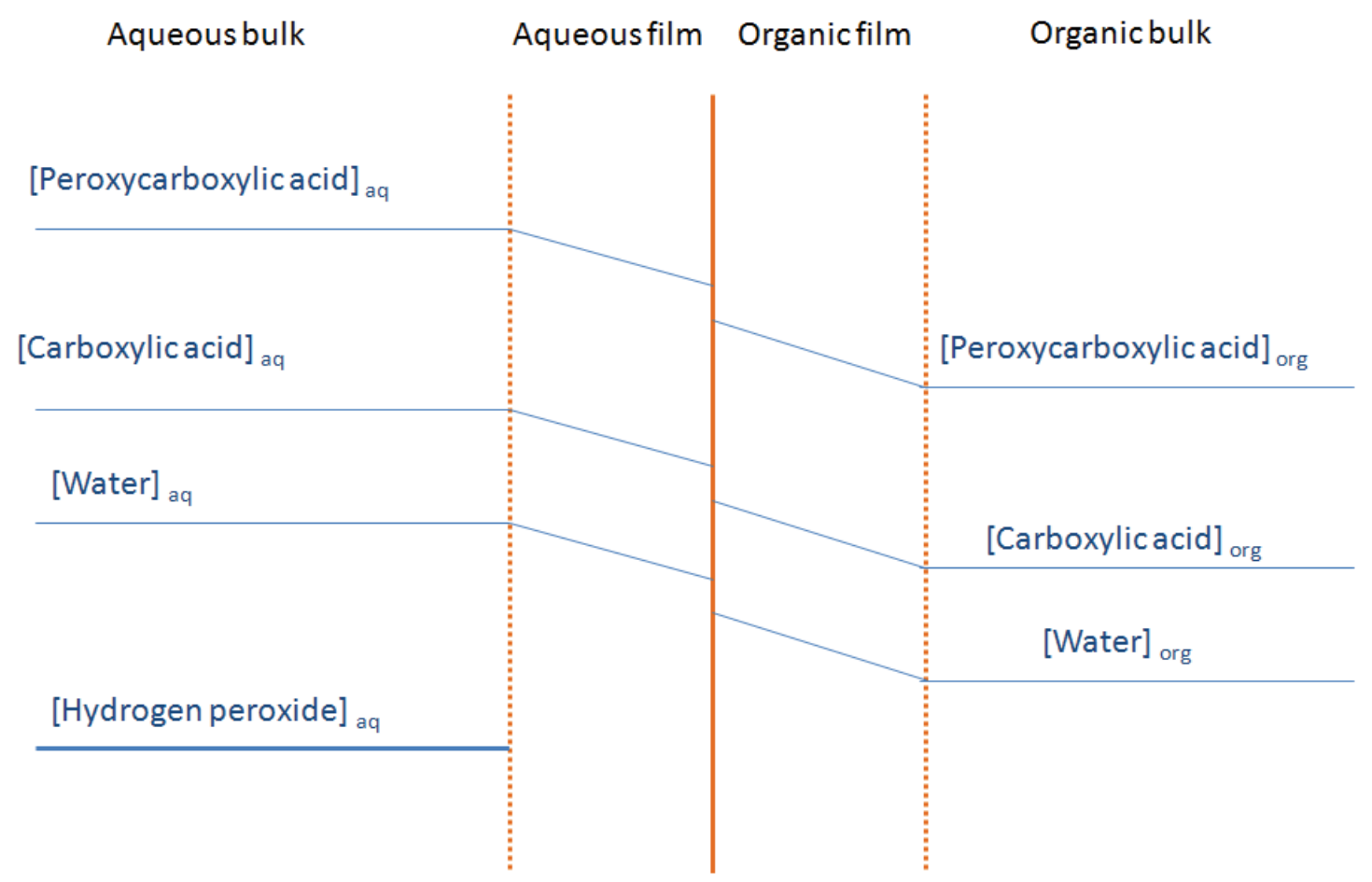

Fig. 4. Concentration profiles for aqueous species. 

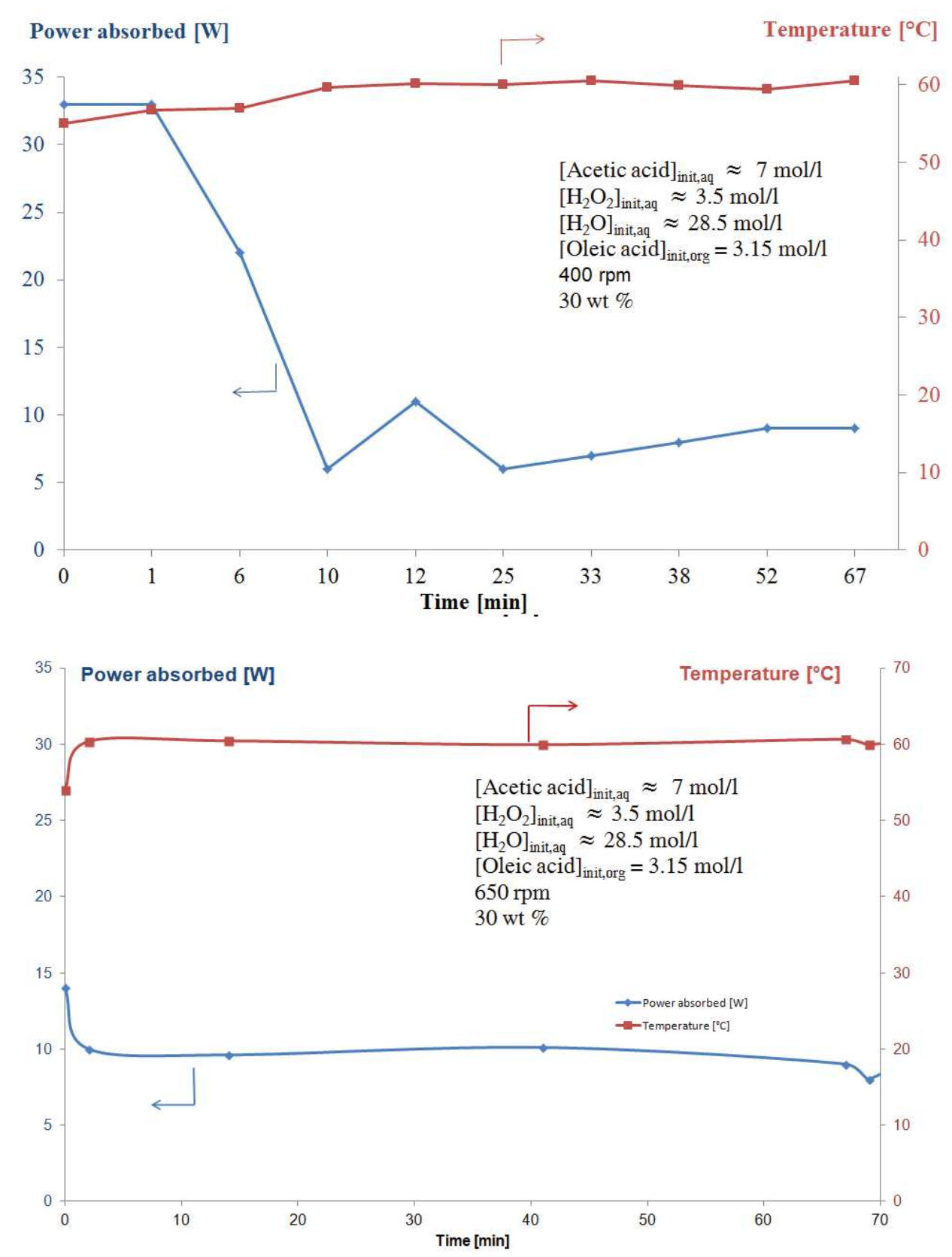

Fig. 5. Evolution of the temperature towards the absorbed and reflected power for a $30 \mathrm{wt} . \%$ of organic phase mixture at 400 and $650 \mathrm{rpm}$. 

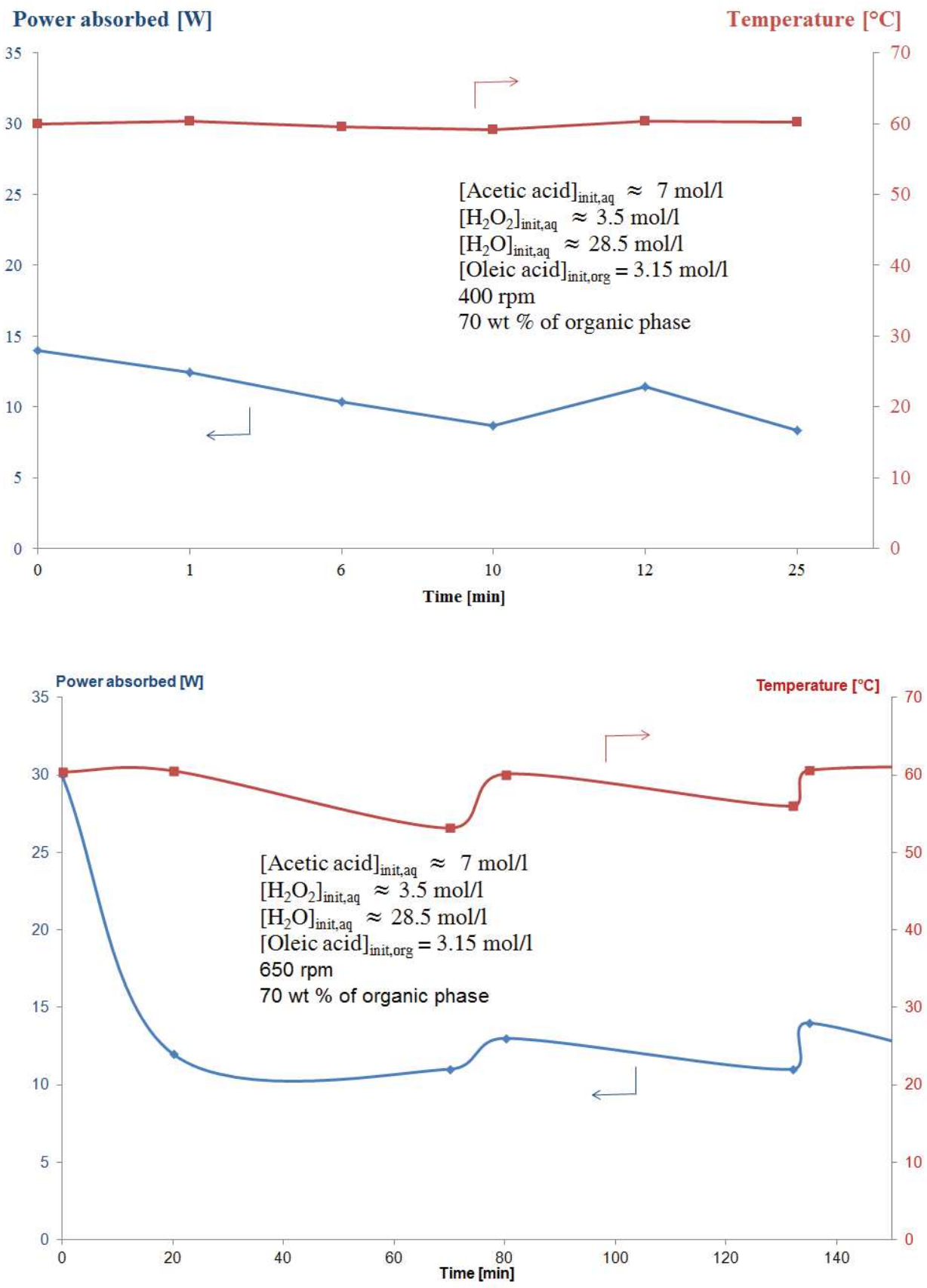

Fig. 6. Evolution of the temperature towards the absorbed and reflected power for a $70 \mathrm{wt} . \%$ of organic phase mixture at 400 and $650 \mathrm{rpm}$. 


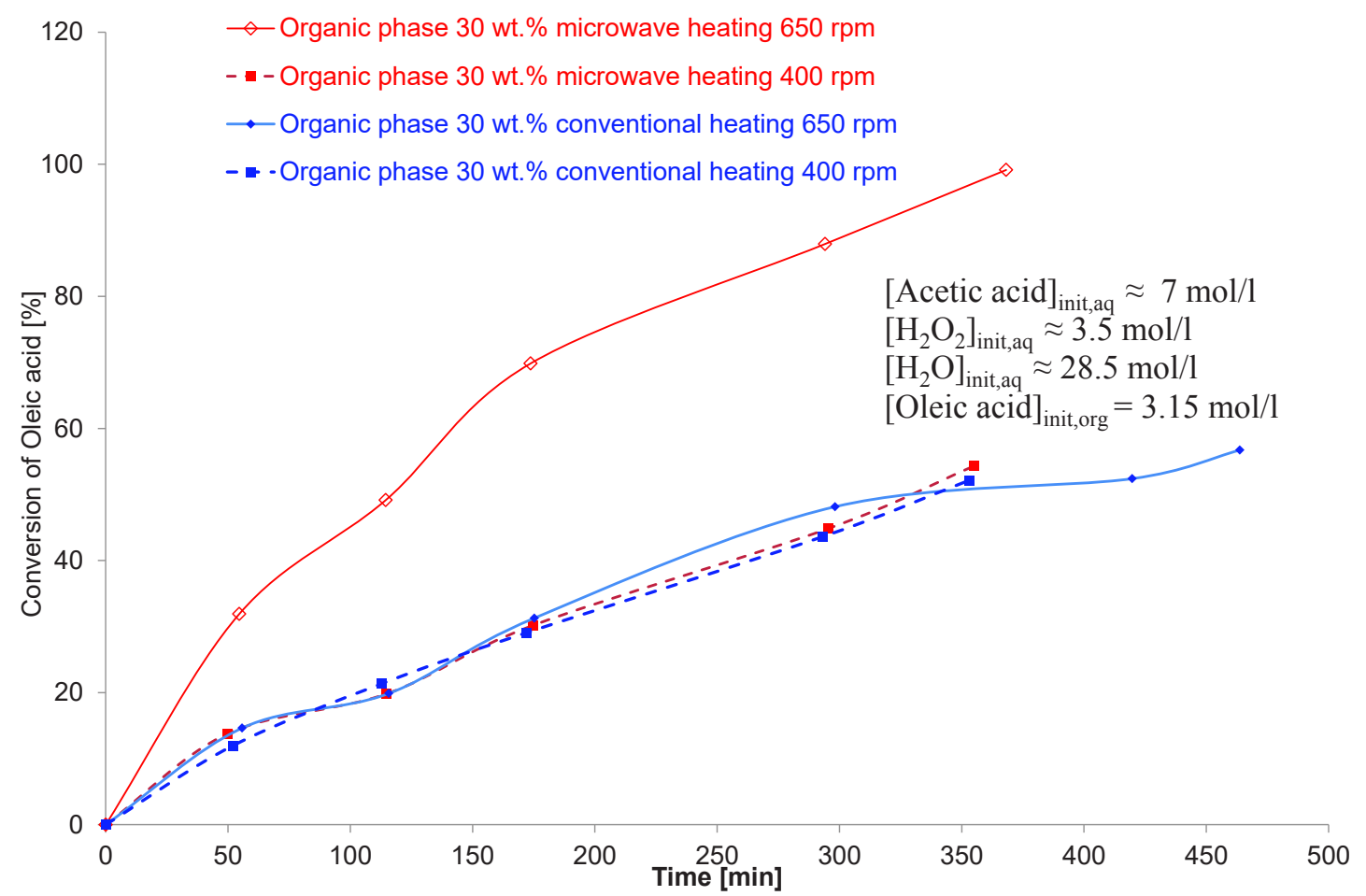

Fig. 7. Effect of the stirring speed on the oleic acid conversion at $60^{\circ} \mathrm{C}$ in the presence of acetic acid. 


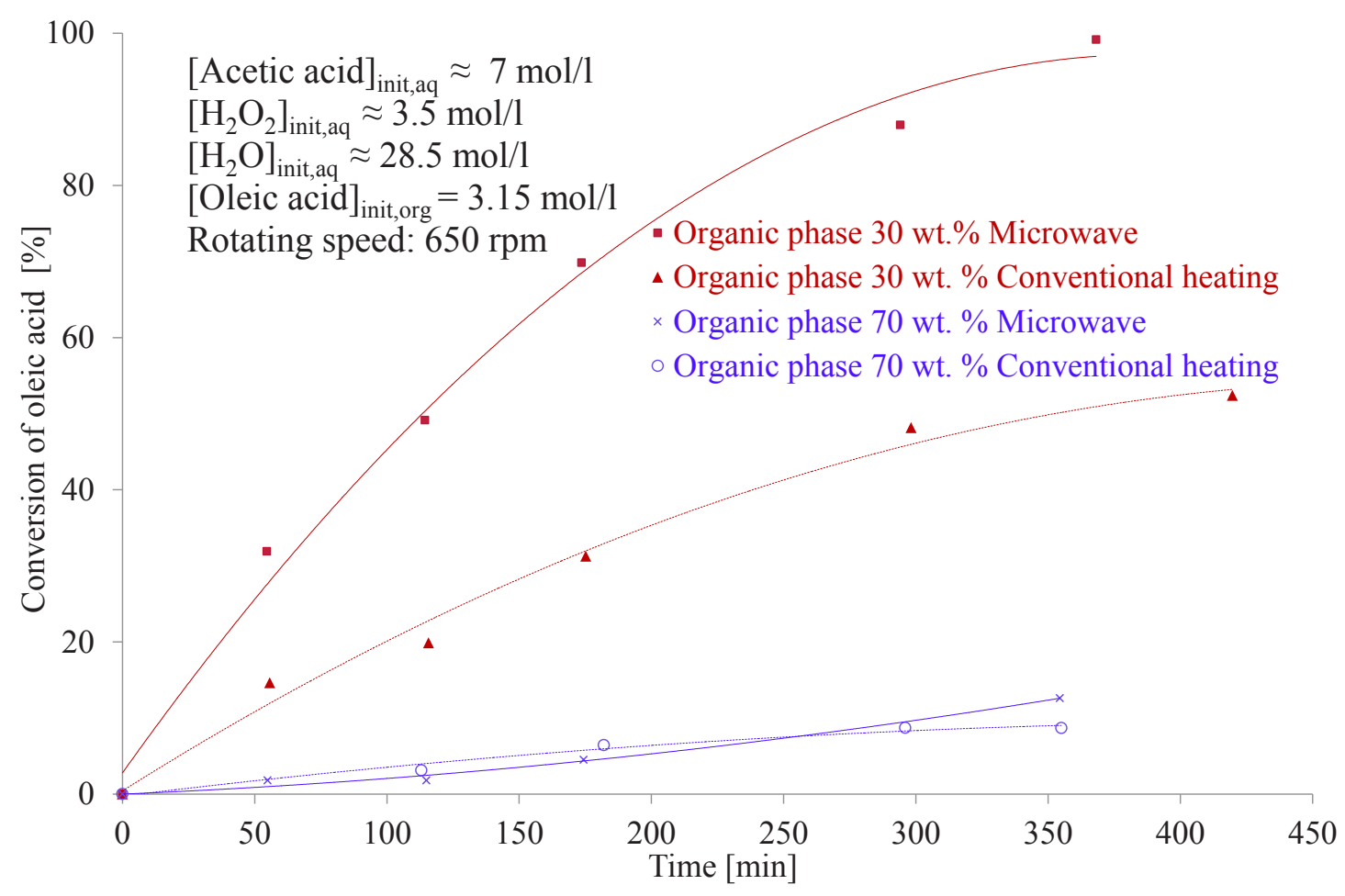

Fig. 8. Influence of the heating source and nature of the continuous phase on the oleic acid conversion in the presence of acetic acid at $650 \mathrm{rpm}$ and $60^{\circ} \mathrm{C}$. 


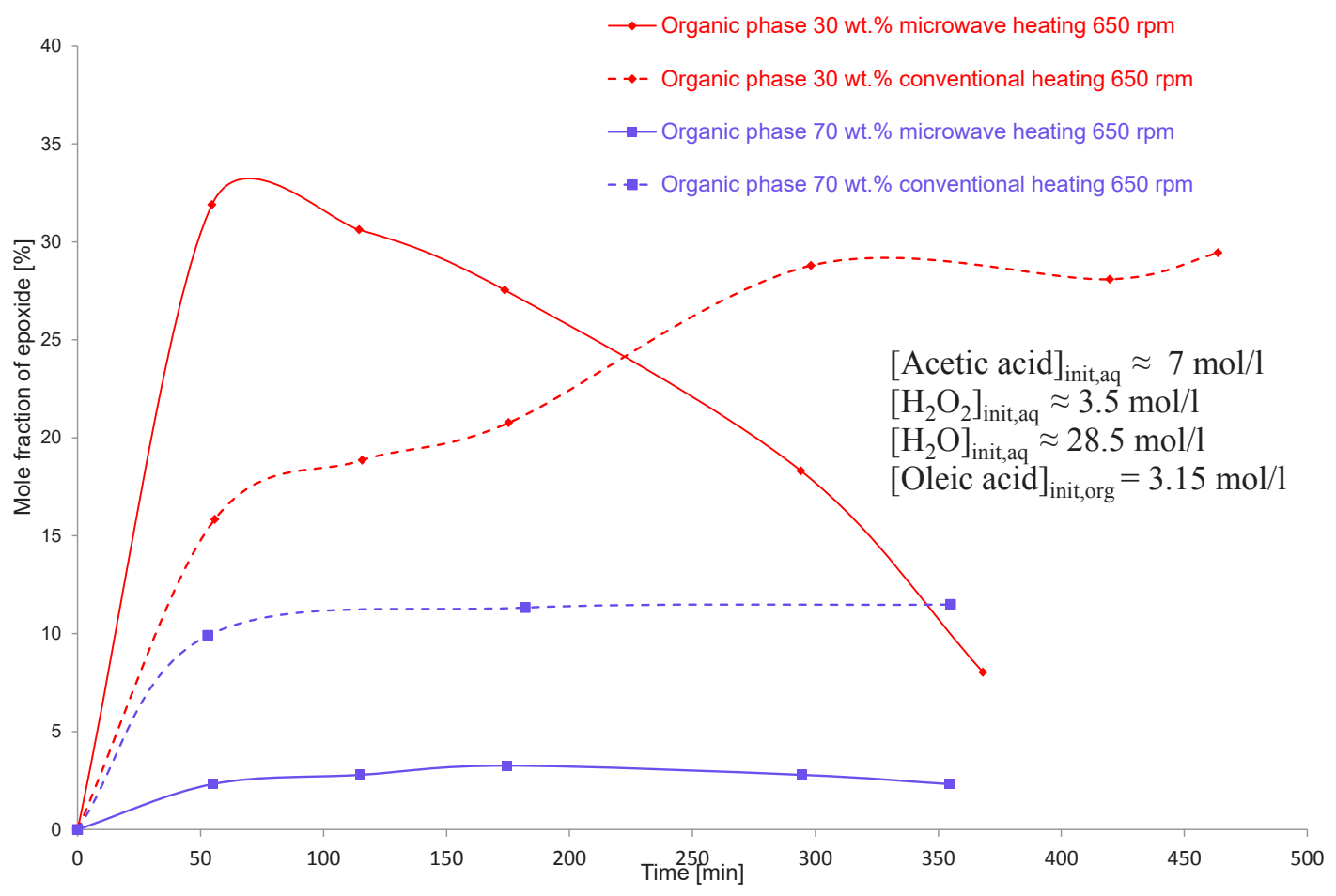

Fig. 9. Influence of the heating source and nature of the continuous phase on the mole fraction of epoxide in the presence of acetic acid at $650 \mathrm{rpm}$ and $60^{\circ} \mathrm{C}$. 


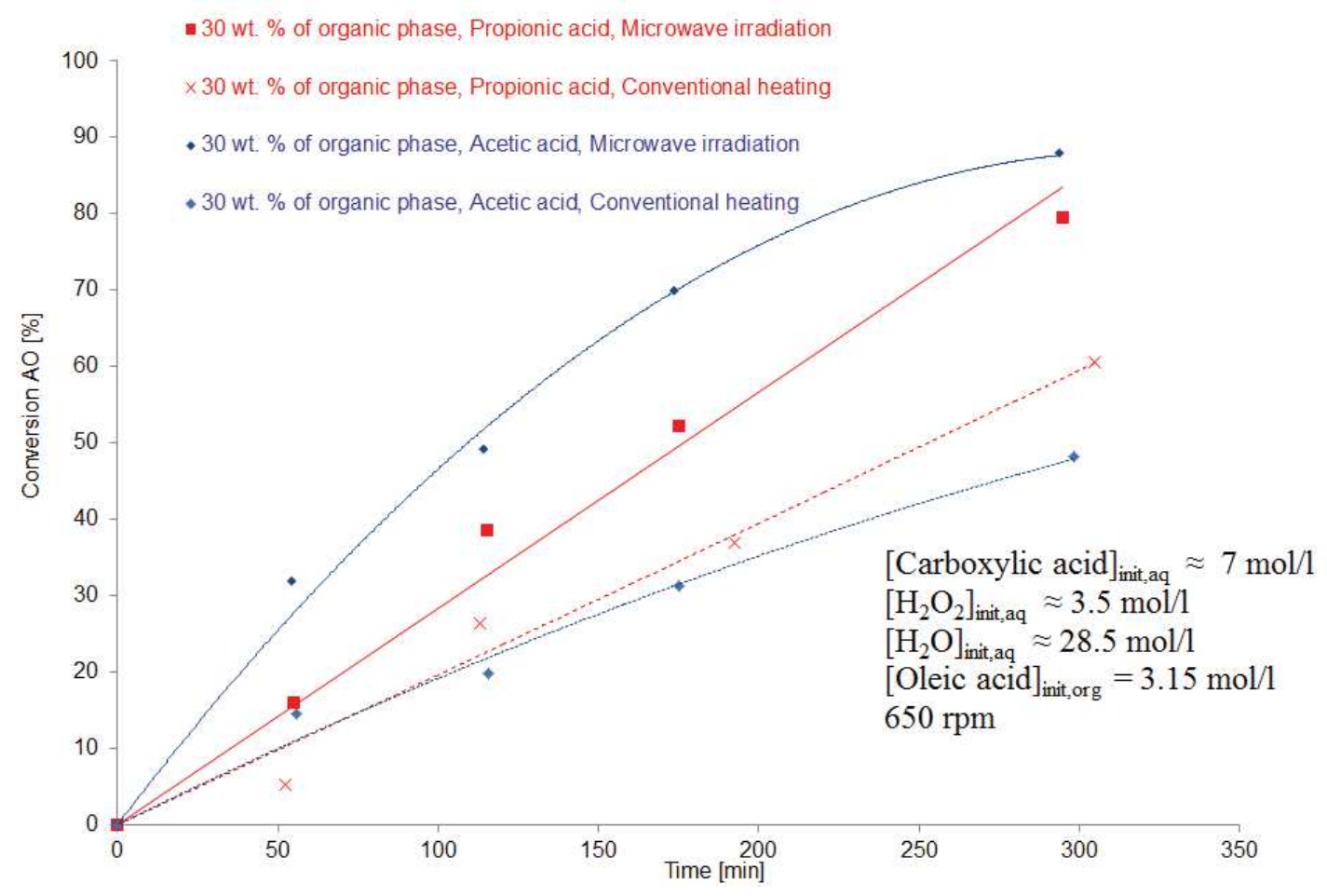

Fig. 10. Conversion of oleic acids under conventional and microwave heating using different carboxylic acid at $650 \mathrm{rpm}$ and $60^{\circ} \mathrm{C}$. 


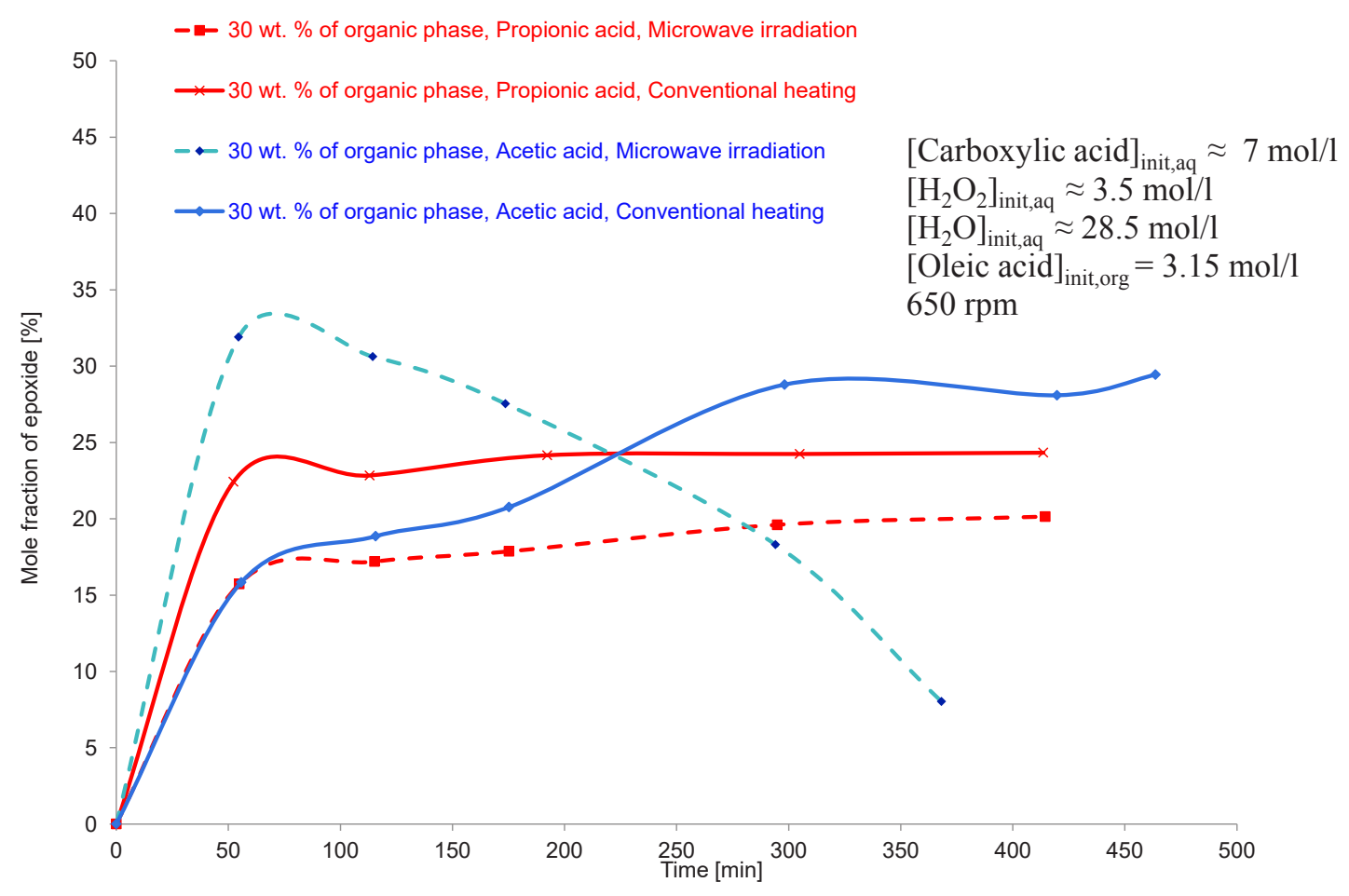

Fig. 11. Influence of the heating source and nature of the continuous phase on the mole fraction of epoxide at $650 \mathrm{rpm}$ and $60^{\circ} \mathrm{C}$. 
Table 1. Evolution of the Reynolds number at $60^{\circ} \mathrm{C}$.

\begin{tabular}{|c|c|c|c|c|}
\cline { 2 - 5 } \multicolumn{1}{c|}{} & \multicolumn{2}{c|}{$30 \%$ organic phase } & \multicolumn{2}{c|}{$70 \%$ organic phase } \\
\hline Rotation speed & $\operatorname{Re}($ initial) & $\operatorname{Re}($ final) & $\operatorname{Re}$ (initial) & $\operatorname{Re}$ (final) \\
\hline $400 \mathrm{rpm}$ & 2997 & 34 & 2846 & 14 \\
\hline $650 \mathrm{rpm}$ & 4870 & 54 & 4624 & 22 \\
\hline
\end{tabular}


Table 2. Experimental matrix.

\begin{tabular}{|c|c|c|}
\hline Reaction temperature & \multicolumn{2}{|c|}{$60^{\circ} \mathrm{C}$} \\
\hline Rotation speed & \multicolumn{2}{|c|}{$300-650 \mathrm{rpm}$} \\
\hline Initial amount of oleic acid & $30-70 \mathrm{wt} . \%$ & $0.05-0.11 \mathrm{~mol}$ \\
\hline Initial amount of carboxylic acid & $0-30 \mathrm{wt} . \%$ & $0.00-0.22 \mathrm{~mol}$ \\
\hline Initial $\mathrm{H}_{2} \mathrm{O}_{2}$ amount & $3-10 \mathrm{wt} . \%$ & $0.05-0.11 \mathrm{~mol}$ \\
\hline Initial $\mathrm{H}_{2} \mathrm{O}$ amount & $16-65 \mathrm{wt} . \%$ & $0.20-1.5 \mathrm{~mol}$ \\
\hline Reaction volume & \multicolumn{2}{|c|}{$50 \mathrm{ml}$} \\
\hline
\end{tabular}


Table 3. Sauter number at different rotating speed.

\begin{tabular}{|c|c|c|}
\hline Rotation speed & Organic phase 30 wt. $\%$ & Organic phase 70 wt. $\%$ \\
\hline $400 \mathrm{rpm}$ & $\mathrm{d}_{32}=582 \mu \mathrm{m}$ & $\mathrm{d}_{32}=831 \mu \mathrm{m}$ \\
\hline $650 \mathrm{rpm}$ & $\mathrm{d}_{32}=268 \mu \mathrm{m}$ & $\mathrm{d}_{32}=382 \mu \mathrm{m}$ \\
\hline
\end{tabular}


Table 4. Initial rate of epoxide formation.

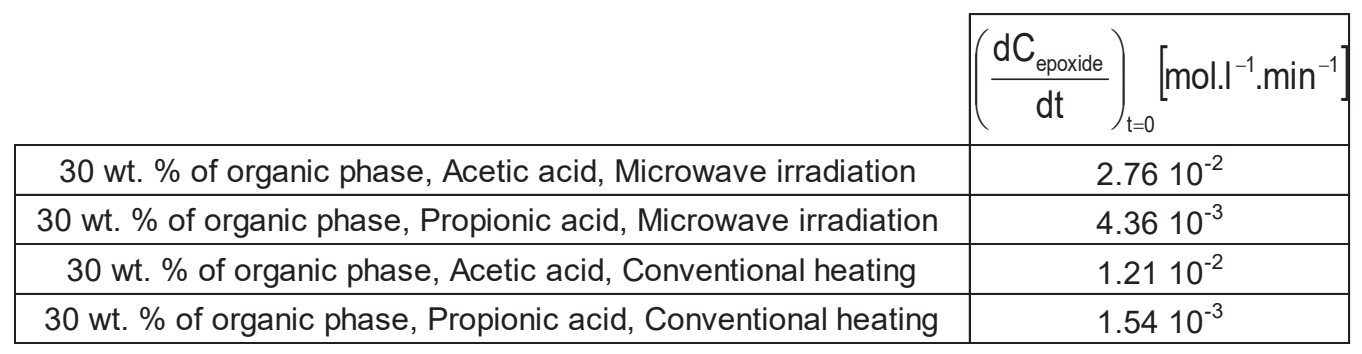

